\title{
KELIO SĄNARIO KREMZLE்S PAŽEIDIMŲ LAIPSNIO IR DAŽNIO PRIKLAUSOMYBE் NUO LYTIES, AMŽIAUS IR DAŽNIAUSIAI PAŽEIDŽIAMOS SRITYS
}

\author{
Rimtautas Gudas ${ }^{1,2}$, Eimantas Spitrys ${ }^{3}$ \\ ${ }^{1}$ Lietuvos sveikatos moksly universiteto Medicinos akademijos Ortopedijos-traumatologijos klinika, \\ ${ }^{2}$ Lietuvos sveikatos mokslu universiteto Medicinos akademijos Sporto institutas, \\ ${ }^{3}$ Lietuvos sveikatos mokslu universiteto Medicinos akademija
}

Raktažodžiai: kelio sąnario kremzlès pažeidimai, osteochondriniai defektai, dažniausiai pažeidžiamos kelio sąnario kremzlès sritys, kelio sąnario pažeidimo priklausomybė nuo lyties, kelio sąnario pažeidimo priklausomybė nuo amžiaus.

\section{Santrauka}

Kelio sąnario kremzlès pažeidimai yra dažna ir aktuali problema. Pažeidimams įtakos turi lytis, amžius, rasè, genetiniai veiksniai, nutukimas, traumos, buvę uždegiminiai procesai. Šis tyrimas rodo kelio sąnario kremzlès pažeidimų priklausomybę nuo pagrindinių rizikos faktorių: amžiaus, lyties; dažniausiai pažeidžiamas kelio sąnario kremzlès sritis ir vyraujančius pažeidimo laipsnius, jų dažnị atskirose amžiaus grupèse.

Rezultatai. I tyrimą buvo ịtraukti 1145 pacientai, kuriems kelio sąnario artroskopijos metu buvo vertinta kelio sąnario kremzlès pažeidimo laipsnis ir sritis. Vidutinis tiriamujų pacientu amžius metais buvo $45,97 \pm 16,71$. Nustatyta, kad kelio sąnario kremzlès defektai bendrai buvo diagnozuoti $65,0 \%$ pacientų,o defektų nebuvo diagnozuota $35,0 \%$ pacientų. Palyginti vyrai ir moterys pagal tai, ar tarp juc pažeidimai ịvyksta dažniau arba pažeidimų konkrečiam pacientui būna daugiau, apskaičiuota $p$ reikšmé $<0,05$ ir Mann-Whitney vidutiniai rangai rodo, kad moterų grupejje pažeidimai pasitaikè dažniau. Kelio sąnario kremzlès I laipsnio pažeidimai bendrai buvo nustatyti $9,4 \%$ pacientų, II laipsnio $43,9 \%$, III laipsnio - 31,1\%, IV laipsnio - 15,6\%. I laipsnio pažeidimai statistiškai reikšmingai dažniau pasitaikè vyrams $\mathrm{p}<0,05$, o II ir III moterims $\mathrm{p}<0,05$, IV laipsnio pažeidimų skirtumų tarp lyčių nenustatyta, $p>0,05$. Operacijų metu buvo diagnozuota 3770 skirtingų sričių pažeidimų: vyrams
$37,3 \%$, moterims $62,7 \%$. Spearmen'o ranginès koreliacijos tarp pažeidimų kiekio konkrečiam pacientui ir paciento amžiaus gauta $\mathrm{p}$ reikšmė $<0,05$ rodo, kad koreliacija statistiškai reikšminga. Koreliacija 0,48 - stipri, teigiama, rodo, kad vyresniems pacientams pažeidimai pasitaikè dažniau.

Išvados. Lytis ir amžius yra statistiškai reikšmingas faktorius kelio sąnario kremzlès pažeidimo laipsniui ir dažniui. Dažniausiai pažeidžiamos kelio sąnario kremzlès sritys yra F3-F4 šlaunikaulio vidinio krumplio kremzlè, P3-P4 girnelès kremzlè, T4-T5 blauzdikaulio vidinio krumplio kremzlè. Nuo 45-55 metų ženkliai didejja kelio sąnario kremzlès pažeidimų kiekis ir pažeidimo laipsnis.

\section{İvadas}

Kelio sąnario kremzlès pažeidimai yra dažna ir aktuali problema [1]. Pažeidimams ịtakos turi lytis, amžius, rasé, genetiniai veiksniai, nutukimas, traumos, buvę uždegiminiai procesai [2]. Kelio sąnario kremzlès pažeidimai sunkiai gyja ir ilgainiui gali išsivystyti osteoartritas [3]. Kremzlès gydymo indikacijos priklauso nuo daugelio faktorių: pažeidimo vietos, gylio, paciento amžiaus, pažeidimo sukeliamų simptomų ir kelio funkcijos [1]. Šiuolaikiniai osteoartrito gydymo būdai negali pilnai atstatyti degeneravusios kremzlès funkcijos, todèl norint sustabdyt tolimesnę kremzlès degeneraciją labai svarbu ịvertinti rizikos veiksnius, laiku nustatyti kremzlès pažeidimus ir pritaikyti patị efektyviausią gydymą [4]. Šis tyrimas rodo kelio sąnario pažeidimų priklausomybę nuo pagrindinių rizikos faktorių: amžiaus, lyties, dažniausiai pažeidžiamas kelio sąnario kremzlès sritis,vyraujančius pažeidimo laipsnius ir jų dažnį atskirose amžiaus grupėse LSMU Kauno klinikose operuotiems pacientams, kuriems buvo atliktos kelio sąnario artroskopijos. 
1 lentelè. Pacientų amžiaus vidurkiai

Sutrumpinimai: $S D$ - standartinis nuokrypis (angl. standart deviation)

\begin{tabular}{|l|c|c|}
\hline & Vidurkis metais & SD \\
\hline Moterys & 52,44 & 15,88 \\
\hline Vyrai & 40,08 & 15,21 \\
\hline Bendras & 45,97 & 16,71 \\
\hline
\end{tabular}

2 lentelè. Pažeistų ir nepažeistų kelio sąnario kremzlių pasiskirstymas tarp lyčių

\begin{tabular}{|l|l|l|l|l|}
\hline & & Bendrai & Vyrai & Moterys \\
\hline \multirow{2}{*}{ Pažeidimas } & Taip & $65,0 \%$ & $52,4 \%$ & $75,3 \%$ \\
\cline { 2 - 5 } & $\mathrm{Ne}$ & $35,0 \%$ & $47,6 \%$ & $24,7 \%$ \\
\hline & \multicolumn{4}{|c|}{$\mathrm{p}<0,05$} \\
\hline
\end{tabular}

Darbo tikslas: atrinkti pacientus, kuriems buvo atliktos kelio sąnario artroskopinès operacijos ir jų metu įvertinta kelio sąnario kremzlès būklè. Nustatyti pažeidimų dažnio ir pažeidimo laipsnio priklausomybę nuo lyties, amžiaus, kokio laipsnio ir kaip dažnai pažeidimai vyrauja atskirose amžiaus grupėse; nustatyti dažniausiai pažeidžiamas kelio sąnario kremzlès sritis.

\section{Metodai}

Tyrimo metu buvo atlikta retrospektyvinè analizè pagal LSMU ligoninès Kauno klinikų Ortopedijos-traumatologi-

4 lentelè. Šlaunikaulio sąnarinio paviršiaus kremzlès pažeidimų sričių pasiskirstymas

\begin{tabular}{|l|c|c|c|c|c|c|c|c|c|c|}
\hline Sritis & F1 & F2 & F3 & F4 & F5 & F6 & F7 & F8 & F9 & F10 \\
\hline Dažnis & $2,9 \%$ & $1,4 \%$ & $13,6 \%$ & $13,4 \%$ & $5,6 \%$ & $5,4 \%$ & $0,2 \%$ & $0,3 \%$ & $2,1 \%$ & $2,0 \%$ \\
\hline
\end{tabular}

5 lentelė. Blauzdikaulio sąnarinio paviršiaus kremzlès pažeidimų sričių pasiskirstymas

\begin{tabular}{|l|c|c|c|c|c|c|c|c|c|c|}
\hline Sritis & T1 & T2 & T3 & T4 & T5 & T6 & T7 & T8 & T9 & T10 \\
\hline Dažnis & $3,0 \%$ & $0,5 \%$ & $1,0 \%$ & $8,1 \%$ & $7,5 \%$ & $0,3 \%$ & $0,1 \%$ & $0,0 \%$ & $3,1 \%$ & $3,1 \%$ \\
\hline
\end{tabular}

6 lentelè. Girnelès sąnarinio paviršiaus kremzlès pažeidimų sričių pasiskirstymas

\begin{tabular}{|l|c|c|c|c|c|c|}
\hline Sritis & $\mathrm{P} 1$ & $\mathrm{P} 2$ & $\mathrm{P} 3$ & $\mathrm{P} 4$ & $\mathrm{P} 5$ & $\mathrm{P} 6$ \\
\hline Dažnis & $2,3 \%$ & $2,4 \%$ & $8,9 \%$ & $9,0 \%$ & $1,9 \%$ & $1,9 \%$ \\
\hline
\end{tabular}

7 lentelè. Kremzlès pažeidimų dažnis skirtingose amžiaus grupėse

\begin{tabular}{|c|c|c|c|c|c|c|c|c|}
\hline & Amžius & $<25$ & $25-35$ & $35-45$ & $45-55$ & $55-65$ & $65-75$ & $>75$ \\
\hline \multirow{2}{*}{ Pažeidimas } & Taip & $28,5 \%$ & $41,4 \%$ & $57,9 \%$ & $78,4 \%$ & $87,1 \%$ & $80,1 \%$ & $84,4 \%$ \\
\cline { 2 - 8 } & Ne & $71,5 \%$ & $58,6 \%$ & $42,1 \%$ & $21,6 \%$ & $12,9 \%$ & $19,9 \%$ & $15,6 \%$ \\
\hline
\end{tabular}

8 lentelè. Kremzlès pažeidimų laipsnių dažnis skirtingose amžiaus grupėse

\begin{tabular}{|l|c|c|c|c|c|c|c|c|}
\hline & Amžius & $<25$ & $25-35$ & $35-45$ & $45-55$ & $55-65$ & $65-75$ & $>75$ \\
\hline Laipsnis & I & $29,6 \%$ & $22,0 \%$ & $11,6 \%$ & $9,8 \%$ & $3,3 \%$ & $6,9 \%$ & $3,9 \%$ \\
\cline { 2 - 8 } & II & $56,8 \%$ & $52,3 \%$ & $45,4 \%$ & $45,3 \%$ & $44,4 \%$ & $36,0 \%$ & $30,5 \%$ \\
\cline { 2 - 8 } & III & $7,4 \%$ & $17,0 \%$ & $27,5 \%$ & $32,0 \%$ & $37,9 \%$ & $33,8 \%$ & $35,1 \%$ \\
\cline { 2 - 8 } & IV & $6,2 \%$ & $8,7 \%$ & $15,5 \%$ & $12,9 \%$ & $14,4 \%$ & $23,3 \%$ & $30,5 \%$ \\
\hline
\end{tabular}
mo priklausomybé nuo lyties
3 lentelė. Pažeidimų laipsnių pasiskirstymas tarp lyčių ir pažeidi-

\begin{tabular}{|l|r|r|r|r|l|}
\hline Laipsnis & \multicolumn{2}{|c|}{$\begin{array}{c}\text { Pažeidimų } \\
\text { kiekis }\end{array}$} & \multicolumn{2}{c|}{ Pažeidimai \% } & $\begin{array}{c}\text { p } \\
\text { reikšmė }\end{array}$ \\
\cline { 2 - 6 } & Moterys & Vyrai & Moterys & Vyrai & \\
\hline I & 99 & 113 & $7,2 \%$ & $12,9 \%$ & $\mathrm{p}<0,05$ \\
\hline II & 600 & 388 & $43,7 \%$ & $44,2 \%$ & $\mathrm{p}<0,05$ \\
\hline III & 459 & 242 & $33,4 \%$ & $27,6 \%$ & $\mathrm{p}<0,05$ \\
\hline IV & 216 & 134 & $15,7 \%$ & $15,3 \%$ & $\mathrm{p}>0,05$ \\
\hline Iš viso: & 1374 & 877 & $100 \%$ & $100 \%$ & $\mathrm{p}<0,05$ \\
\hline
\end{tabular}

jos skyriaus 2013 metų operacijų registro knygų duomenis. Atrinktos 2013 metais Ortopedijos-traumatologijos skyriuje atliktos kelio artroskopinès operacijos, kurių metu buvo vertinta kelio sąnario kremzlès pažeidimo laipsnis ir sritys. Buvo nustatyta, kad 2013 metais Ortopedijos-traumatologijos skyriuje atliktos 1175 kelio artroskopinès ir kelio raišçų rekonstrukcinès operacijos. I tyrimą buvo ịtraukta 1145 . atvejai buvo analizuojami naudojant ICRS (International Cartilage Repair Society) kelio vertinimo formą (nuo I iki IV laipsnio) ir kelio sąnario kremzlès žemèlapi, pagal kurị buvo nustatoma tiksli kelio sąnario pažeidimo sritis (F110 - šlaunikaulio sąnarinio paviršiaus, P1-6 - girnelès ir T1-10 - blauzdikaulio) [5]. Buvo įvertintos visos pažeistos sritys kiekvienam pacientui, jų pažeidimo laipsnis, lokalizacija. Pacientai suskirstyti i septynias amžiaus grupes, pacientų grupé nuo 25-75 išskaidyta siekiant detaliau ištirti ir pažiūrèti, nuo kurio amžiaus tarpsnio pažeidimų kiekis ženkliai pradeda didèti tirtų pacientu populiacijoje. Iki 25 metu pacientų grupé detaliau neskaidyta, nes pažeidimu tikètasi retais atvejais, kaip ir neskaidyta vyresnių nei 75 metų pacientų grupé, kur kelio sąnario kremzlès pažeidimų tikètasi aptikti pas daugumą pacientų. Apskaičiuotas tirtų paci- 
entų amžiaus vidurkis ir standartinis nuokrypis. Statistinè analizè atlikta naudojant standartinį statistinị paketą ,SPSS for Windows 21,0". Duomenims analizuoti naudotas chi kvadrato statistinis kriterijus ir palyginta, ar skiriasi skirtingų laipsnių pažeidimų dažniai vyrams ir moterims. Chi kvadrato kriterijui naudotos proporcijos, pakoreguotos pagal pažeidimus patyrusių vyrų ir moterų skaičiu ir buvo įtraukti pasikartojantys skirtingų sričių pažeidimai tam pačiam pacientui. Naudojant Mann-Whitney statistinį kriterijų palyginti vyrai ir moterys pagal tai, ar tarp jų pažeidimai ivvyksta dažniau. Apskaičiuojant Spearmen'o ranginę koreliaciją tarp kelio sąnario pažeidimų kiekio konkrečiam pacientui ir paciento amžiaus, nustatytas ryšys tarp pažeidimu dažnio ir amžiaus. Pasirinkta $p$ reikšmè mažesnė nei 0,05 rodo, kad skirtumai statistiškai reikšmingi.

\section{Rezultatai}

I tyrimą buvo įtraukti 1145 pacientai. 1 lenteleje pateikiama tirtu pacientų amžiaus vidurkis. 2 lentelèje pateikiama tirtų pacientų pažeistų ir nepažeistų kelio sąnario kremzlių dažniai. Buvo palyginti vyrai ir moterys pagal tai, ar tarp jų pažeidimai ịvyksta dažniau arba pažeidimų konkrečiam pacientui būna daugiau. Apskaičiuota $\mathrm{p}$ reikšmé $<0,05(\mathrm{p}<0,001)$ ir Mann-Whitney vidutiniai rangai rodo, kad moteru grupejje pažeidimai pasitaikè dažniau. 3 lentelèje pateikiama, kaip dažnai I, II, III, IV laipsnio pažeidimų pasitaikè vyrams ir moterims. I laipsnio pažeidimai statistiškai reikšmingai dažniau pasitaikè vyrams, o II ir III moterims. Vertinant IV laipsnio pažeidimus, skirtumų tarp lyčių nenustatyta. Vertinant pažeidimus bendrai, pažeidimai statistiškai reikšmingai dažniau pasitaikè moterims, nei vyrams $\mathrm{p}<0,05$.

Operacijų metu buvo diagnozuota 3770 skirtingų sričių pažeidimų: vyrams $37,3 \%$, moterims $62,7 \%$. Buvo nustatyta šlaunikaulio (4 lentelè), blauzdikaulio (5 lentelè) ir girnelès (6 lentelè) sąnarinio paviršiaus kremzlès pažeidimų sričių dažniai.

Suskirsčius pacientus ị septynias amžiaus grupes nustatytas pažeidimų dažnis (7 lentelè) ir pažeidimo laipsnių (8 lentelè) pasiskirstymas skirtingose amžiaus grupèse. Apskaičiuotos Spearmen'o ranginès koreliacijos tarp pažeidimų kiekio konkrečiam pacientui ir paciento amžiaus, $p$ reikšmé $<0,05(\mathrm{p}<0,001)$ rodo, kad koreliacija statistiškai reikšminga. Koreliacija 0,48 - stipri, teigiama, rodo, kad vyresniems pacientams pažeidimai pasitaikè dažniau.

\section{Išvados}

Lytis yra statistiškai reikšmingas faktorius kelio sąnario kremzlès pažeidimo laipsniui ir dažniui, nes moterims nustatytas operacijų metu pažeidimo laipsnis yra didesnis ir pažeidimai pasitaiko dažniau nei vyrams. Dažniausiai pažeidžiamos kelio sąnario kremzlès sritys yra: F3-F4 šlaunikaulio vidinio krumplio kremzlè, P3-P4 girnelès kremzlè, T4-T5 blauzdikaulio vidinio krumplio kremzlè. Amžius yra statistiškai reikšmingas faktorius kelio sąnario kremzlès pažeidimo dažniui, vyresniems pacientams kelio sąnario artroskopijų metu kremzlès pažeidimai buvo nustatomi dažniau nei jaunesniems pacientams. Amžius turi itakos pažeidimo laipsnio dydžiui, kuo vyresnis pacientas, tuo didesnio laipsnio pažeidimai buvo nustatomi. Nustatyta, kad jaunesnių nei 25 metų pacientų grupejje vyrauja II laipsnio pažeidimai. 25-35 metų - II laipsnio. 35-45 metų - II,III laipsnio. 45-55 metų - II,III laipsnio. 55-65 metų II,III laipsnio. 65-75 metu - II,III,IV laipsnio. Vyresnių nei 75 metų II, III ir IV laipsnio pažeidimai. Nuo 45-55 metų ženkliai didejja kelio sąnario kremzlès pažeidimų kiekis ir pažeidimo laipsnis.

\section{Literatūra}

1. Solheim E, Krokeide AM, Melteig P, Larsen A, Strand T, Brittberg M. Symptoms and function in patients with articular cartilage lesions in 1,000 knee arthroscopies. Knee Surg Sports Traumatol Arthrosc 2014.

2. Sambrook P, Shrieber L, Taylor T, Ellis MA. Raumenų ir skeleto sistema. Pagrindai ir klinikinès būklès. Vilnius: UAB ,Vaistų žinios“", 2012; 77-96.

3. Falah M, Nierenberg G, Soudry M, Hayden M, Volpin G. Treatment of articular cartilage lesions of the knee. Int Orthop 2010; 34(5): 621-630.

4. Casula V, Hirvasniemi J, Lehenkari P, Ojala R, Haapea M, Saarakkala S, Lammentausta E, Nieminen MT. Association between quantitative MRI and ICRS arthroscopic grading of articular cartilage. Knee Surg Sports Traumatol Arthrosc 2014.

5. Brittberg M, Aglietti P, Gambardella R, Hangody L, Hauselmann HJ, Jakob RP, Levine D, Lohmander S, Mandelbaum BR, Peterson L, Staubli HU. ICRS Cartilage Injury Evaluation Package 2000; 12-16.

\section{KNEE ARTICULAR CARTILAGE LESIONS DEGREE AND FREQUENCY DEPENDENCE ON GENDER, AGE AND MOST COMMONLY DAMAGED CARTILAGE AREAS \\ R. Gudas, E. Spitrys}

Key words: knee articular cartilage lesions, osteochondral defects, knee articular cartilage lesions dependence on age, most commonly damaged areas of knee articular cartilage, knee articular cartilage lesions dependence on gender.

Summary

Knee articular cartilage lesions are a common and relevant problem. Lesions are influenced by gender, age, race, genetic factors, obesity, trauma, previous inflammatory processes. Modern methods of treatment of osteoarthritis can't fully restore degene- 
rated cartilage normal function, so it is very important to assess risk factors and identify lesions of cartilage in time and choose the most effective treatment to stop further cartilage degeneration. This study shows the knee articular cartilage lesions dependence on key risk factors: age, gender, most vulnerable cartilage areas and the prevailing degree of lesions and their incidence in different age groups who had knee arthroscopic operations.

Results. The study included 1145 patients who had knee joint arthroscopic operations during which were rated knee cartilage lesions degree and area according to the cartilage evaluation map and ICRS (International Cartilage Repair Society) form. The average age of studied patients was $45.97 \pm 16.71$. It was found that the knee articular cartilage defects were found in $65.0 \%$ of patients. No lesions were found in $35.0 \%$ of the patients. When men and women were compared according to whether lesions occur more frequently or which patient has more lesions p-value was calculated $<0.05$ and the Mann-Whitney average ratings show that lesions for women occurred more frequently. Knee articular cartilage I degree lesions were generally found $9.4 \%$ of all the lesions, II degree $43.9 \%$, III degree $-31.1 \%$, IV degree $-15.6 \%$. I degree lesions statistically significantly were more frequent for men $\mathrm{p}<0.05$, II and III for women $\mathrm{p}<0.05$, IV degree lesions statistically significant differences between gender were not found $p>0.05$. During arthroscopies 3770 lesions of different areas were found: men $37.3 \%$, women $62.7 \%$. Damaged areas distribution for both genders were: F1 2.9\%, F2 1.4\%, F3 13.6\%, F4 13.4\%, F5 5.6\%, F6 5.4\%, F7 $0.2 \%$, F8 0.3\%, F9 2.1\%, F10 2.0\%, P1 2.3\%, P2 2.4\%, P3 8.9\%, P4 9.0\%, P5 1.9\%, P6 1.9\%, T1 3.0\%, T2 0.5\%, T3 1.0\%, T4 $8.1 \%$, T5 7.5\%, T6 0.3\%, T7 0.1\%, T8 0.0\%, T9 3.1\%, T10 3.1\%. Patients were divided into seven age groups and it was found that for patients group under 25 years, various degree knee articular cartilage lesions were found in $28.5 \%$ of the knees and in $71.5 \%$ no lesions were found. For patients 25-35 years old lesions were found in $41.4 \%$ of the knees and in $58.6 \%$ cases no lesions were found. For patients $35-45$ years old lesions were found in $57.9 \%$ of the knees and $42.1 \%$ no lesions were found. For patients $45-55$ years old, lesions were found in $78.4 \%$ of the knees and $21.6 \%$ no lesions were found. For patients 55-65 years old lesions were found in $87.1 \%$ of the knees and $12.9 \%$ no lesions were found. For patients $65-75$ years old lesions were found in $80.1 \%$ of the knees and $19.9 \%$ no lesions were found. For patients older than 75 years, lesions were found in $84.4 \%$ of the knees and $15.6 \%$ no lesions were found. For patients under 25 years I degree lesions were found in $29.6 \%$ of the cases, II degree $-56.8 \%$, III degree $-7.4 \%$, IV degree $-6.2 \%$. For patients $25-35$ years old, I degree lesions were found in $22.0 \%$ of the cases, II $-52.3 \%$, III $-17.0 \%$ IV $-8.7 \%$. For patients $35-45$ years old, I degree lesions were found in $11.6 \%$ of the cases, II $-45.4 \%$, III $-27.5 \%$ IV $-15.5 \%$. For patients $45-55$ years old, I degree lesions were found in $9.8 \%$ of the cases, II $-45.3 \%$, III $-32.0 \%$ IV $-12.9 \%$. For patients $55-65$ years old, I degree lesions were found in $3.3 \%$ of cases, II $-44.4 \%$, III $-37.9 \%$ IV $-14.4 \%$. For patients $65-75$ years old, I degree lesions were found in $6.9 \%$ of the cases, II $-36.0 \%$, III $-33.8 \%$ IV $-23.3 \%$. For older than 75 years patients I degree lesions were found in $3.9 \%$ of the cases, II $-30.5 \%$, III $-35.1 \%$ IV $-30.5 \%$. Spearman's rank correlation between the number of lesions of a particular patient and the patient's age obtained p-value $<0.05$ shows that the correlation is statistically significant. Correlation 0.48 - strong, positive, showing that lesions were found in older people more frequently.

Conclusions. Gender and age are a statistically significant factors for knee articular cartilage lesion degree and frequency. Age affects the size of the lesion degree, the older the patient the greater the degree of damage was determined in the articular cartilage of the knee. From 45-55 years significantly increases the knee articular cartilage lesions quantity and degree of lesions.

The most commonly damaged areas of the knee articular cartilage were F3-F4 internal femoral condyle cartilage, P3-P4 patellar cartilage, T4-T5 internal tibial condyle cartilage.

Correspondence to: eimantas.spitrys@gmail.com

Gauta 2015-04-27 